\title{
Electron Microscopy Characterization of Copper Coatings for Canada's Used Nuclear Fuel Containers
}

\author{
Jason Tam ${ }^{1 *}$, Bosco Yu¹, Weiwei $\mathrm{Li}^{1}$, Jason D. Giallonardo ${ }^{2}$, Jane Y. Howe ${ }^{1}$, and Uwe Erb ${ }^{1}$ \\ 1. Department of Materials Science and Engineering, University of Toronto, Toronto, Ontario, Canada. \\ 2. Nuclear Waste Management Organization, Toronto, Ontario, Canada. \\ * Corresponding author: jht.tam@mail.utoronto.ca
}

Nuclear power supplies about $10 \%$ of the global electricity generation with approximately 450 nuclear reactors globally [1]. Nuclear energy offers many benefits including stable electricity generation and low carbon output; however, one of the biggest challenges of nuclear power is the management of the radioactive fuel waste it generates. Canada's Nuclear Waste Management Organization (NWMO) has proposed a deep geological repository (DGR) solution where used Canada Deuterium Uranium (CANDU) fuel bundles are stored in a used fuel container (UFC), which is then placed at a reference depth of $500 \mathrm{~m}$ underground in a geologically stable rock formation and surrounded by bentonite clay. The UFC is made of a steel core for structural support with a $3 \mathrm{~mm} \mathrm{Cu}$ coating on the surface for corrosion protection (Figure 1a). The $\mathrm{Cu}$ coating is applied onto the partially assembled UFC with a cylindrical body and two hemispherical heads by electrodeposition (ED). Used fuel bundles are placed into the body of the UFC and the container head is bonded to the main body using a hybrid laser arc welding technique to close the UFC. The exposed area of the steel around the weld zone is then coated with $\mathrm{Cu}$ by a cold spray (CS) technique. Finally, the $\mathrm{CS}-\mathrm{Cu}$ coating around the weld zone is annealed to restore the ductility of the CS$\mathrm{Cu}$. Since the $\mathrm{Cu}$ coatings on the container are processed by two different methods, varying microstructures are expected in different regions of the UFC. In this study, extensive microstructural characterizations were performed using various electron microscopy techniques to ultimately develop a better understanding of the structure - mechanical and corrosion behaviour of these Cu coatings.

Three types of $\mathrm{Cu}$ from a prototype UFC were characterized in different directions according to the reference system shown in Figure 1a: $\mathrm{ED}-\mathrm{Cu}$, as-sprayed $\mathrm{CS}-\mathrm{Cu}$, and annealed $\mathrm{CS}-\mathrm{Cu}$. Electron backscattered diffraction (EBSD, Hitachi SU3500 equipped with Oxford EBSD system) was the primary technique utilized, in addition to focused ion beam (FIB, Hitachi NB5000) sectioning and transmission electron microscopy (TEM, Hitachi HF-3300). From these techniques, microstructural characteristics of the $\mathrm{Cu}$ coatings including grain size, grain boundary character distribution, and crystallographic texture were extracted. The microstructure characterization data of ED-Cu in the axial direction is presented in Figure $1 b-d$. From the orientation map (Figure 1b), it is visible that the grains (average grain size: $1.3 \mu \mathrm{m}$ ) of the $\mathrm{Cu}$ is slightly elongated along the growth direction. No significant crystallographic texture was observed. Furthermore, grains are significantly smaller near the steel substrate interface due to an initial $\mathrm{Cu}$ strike layer in the electrodeposition process. This region contains high fraction of nanotwins as shown in FIB prepared cross section image (Figure 1d). The grain boundary character distribution (Figure 1c) indicates that $\mathrm{ED} \mathrm{Cu}$ contain a high fraction (55\%) of $\Sigma 3$ twin boundaries in addition to other special boundaries including $\Sigma 9(10 \%), \Sigma 27(5 \%)$, and all other $\Sigma \leq 29(2 \%)$. The electrodeposition process was optimized to induce a high fraction of low energy $\Sigma 3$ twin boundaries. After annealing at $350^{\circ} \mathrm{C}$ for 1 hour, the $\mathrm{CS}-\mathrm{Cu}$ also demonstrates very similar microstructural characteristics. The average grain size determined from the orientation map is $2.0 \mu \mathrm{m}$ (Figure 1e). The microstructure contains $37 \% \Sigma 3$ twin boundaries as a result of the annealing process. In addition, high fractions of other low $\Sigma$ boundaries were observed $(5 \% \Sigma 1,7 \% \Sigma 9,3 \% \Sigma 27$, and $4 \%$ other $\Sigma \leq 29)$. 
Based on our analysis, both ED-Cu and annealed CS-Cu contain favorable microstructures that is desirable for good mechanical and corrosion performance. Small grain size promotes more uniform corrosion over the surface, rather than localized corrosion attack at grain boundaries of larger grains. Similarly, materials with high fractions of $\Sigma 3$ twin boundaries and other low $\Sigma$ boundaries are known to have better corrosion resistance compared to other random high angle boundaries $(\Sigma>29)$. The results of this study demonstrate that from a microstructure point of view, the corrosion barrier $\mathrm{Cu}$ coatings for Canada's UFC are expected to provide exceptional corrosion performance [3].

\section{References:}

[1] Nuclear Energy Institute, https:/www.nei.org/fundamentals/what-is-nuclear-energy (accessed February 4, 2019)

[2] JD Giallonardo, et al., Proceedings of the $16^{\text {th }}$ International High-Level Radioactive Waste Management Conference (2017) p. 173.

[3] The authors acknowledge the funding source from the Natural Sciences and Engineering Research Council (NSERC) of Canada and the use of the electron microscopy facility in the Ontario Centre for the Characterization of Advanced Materials (OCCAM).

(a)
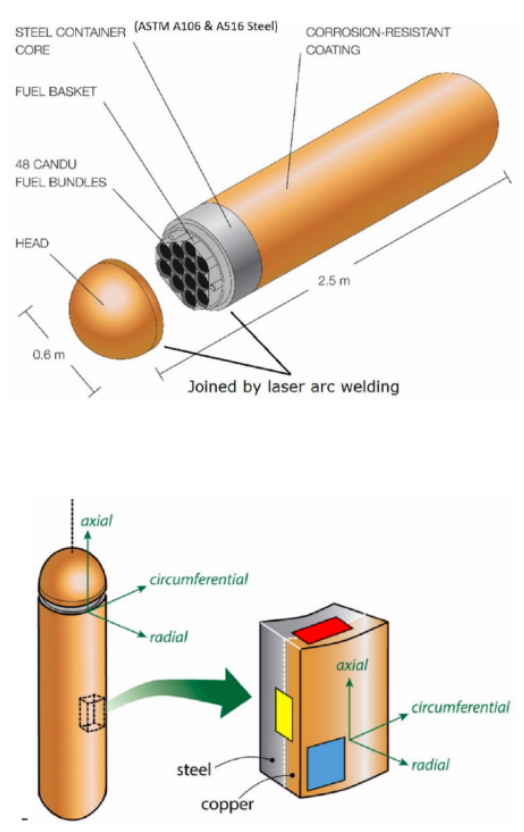
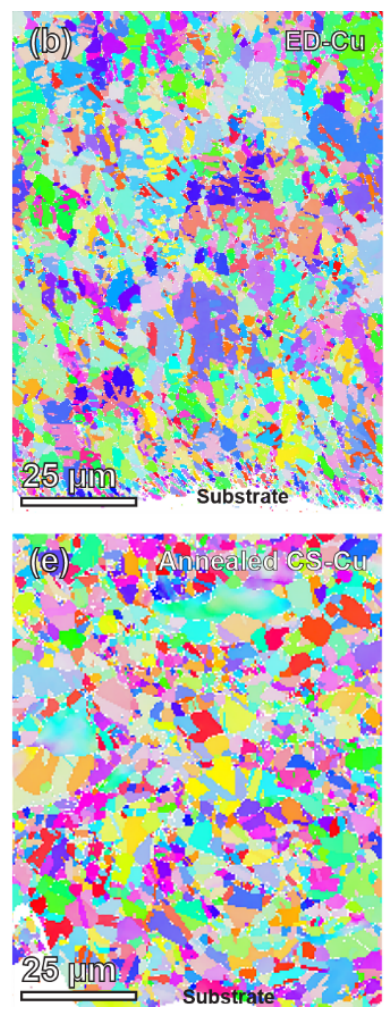
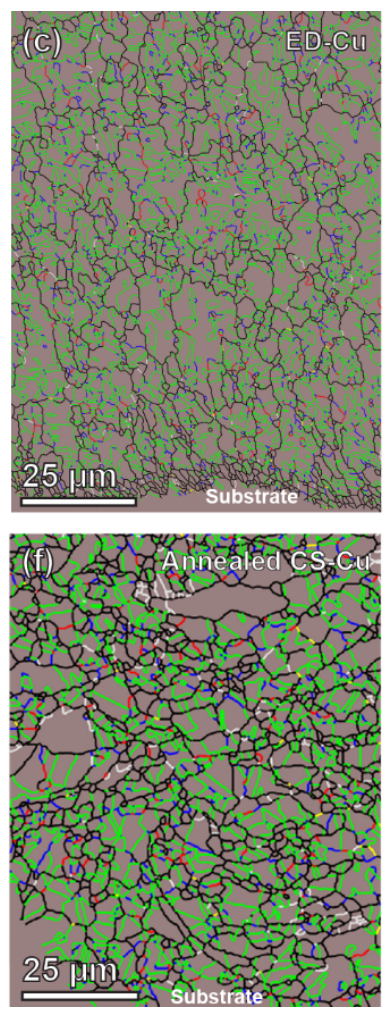

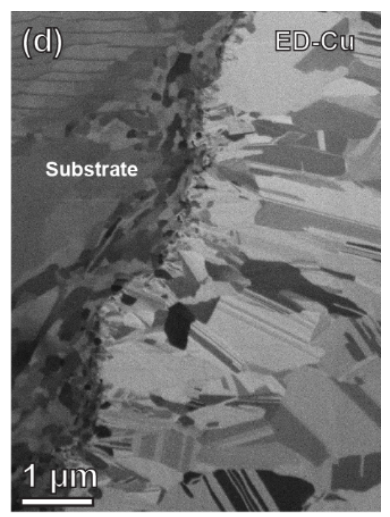

(g))

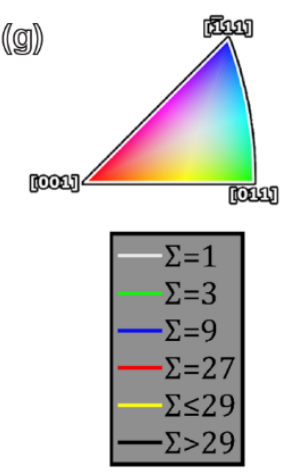

Figure 1. (a) Schematic diagram of the UFC and the coordinate system for characterization. Microstructural characterization of ED $\mathrm{Cu}(\mathrm{b}-\mathrm{d})$ and annealed $\mathrm{CS} \mathrm{Cu}(\mathrm{e}-\mathrm{f})$ in the axial direction. Orientation images are shown in (b) and (e). Grain boundary character maps are shown in (c) and (f). The colour of the grain boundaries represents specific $\Sigma$ boundaries (g). Nanotwins at the interface of ED-Cu and steel can be observed in the FIB cross-section image (d). 